\title{
APLICAÇÃO DAS TÉCNICAS DE ANÁLISE DE INVESTIMENTOS: UM ESTUDO SOB A ÓTICA DA PESQUISA BIBLIOGRÁFICA
}

\author{
Gabriel Santos Gonsalves, Cristiane Cardoso Oliveira, Sonia Sanae Sato \\ Universidade do Oeste Paulista - UNOESTE, Curso de Administração, Presidente Prudente, SP. E-mail: \\ sonia@unoeste.br
}

\section{RESUMO}

Em tempos de constantes mudanças no mercado e do alto nível de competitividade entre organizações, se torna imprescindível que estas realizem investimentos para se destacar frente à concorrência almejando alcançar seus objetivos. Neste contexto, o presente trabalho buscou identificar por meio da pesquisa bibliográfica, no período 2010-2015, os segmentos econômicos que mais utilizaram as técnicas de análise de investimentos, a saber: Valor Presente Líquido, Taxa Interna de Retorno e Payback, para demonstrar a viabilidade dos projetos que pretendiam implantar. O estudo foi do tipo qualitativo, descritivo e bibliográfico. Para a coleta de dados, foi realizado o levantamento de artigos no Banco de Teses e Dissertações da Capes, e após, estes foram analisados. Como resultados, foi possível verificar que as técnicas de análise de investimento utilizadas nos artigos analisados contribuíram para a tomada de decisão das empresas, no sentido de demonstrar-lhes se os projetos propostos eram viáveis ou não para implantação.

Palavras-chave: Técnicas de Análise de Investimentos; Valor Presente Líquido; Taxa Interna de Retorno; Payback.

\section{APPLICATION OF THE TECHNIQUES OF INVESTIMENT ANALYSIS: A STUDY FROM THE PERSPECTIVE OF BIBLIOGRAPHIC RESEARCH}

\begin{abstract}
In times of constant changes on the market and high level of competitiveness between organizations from many different segments, it becomes imperative that these make investments to stand out from the competition and diversify their ways of acting, aiming to achieve their goals. This bias, this exposed tried to identify what the economic segments that more used the techniques of investment analysis, namely: Net Present Value (NPV), Internal Rate of Return (IRR) and Period of Payback, in the period 2010-2015 to demonstrate the viability of the projects that they intend to deploy through research bibliographic. The study was characterized as qualitative, descriptive and publications. For data collection, was initially made a survey of the scientific articles that focused on the issue addressed in this research at the Bank of theses and dissertations from the Coordenação de Aperfeiçoamento de Pessoal de Nível Superior (Capes), and after, the articles selected were analyzed. As a result, it was possible to raise that techniques of investment analysis mentioned have contributed to the decision of the companies, in order to show them if the proposed projects were viable or not of deployment.

Keywords: Techniques of Investment Analysis; Net Present Value, Internal Rate of Return; Payback.
\end{abstract}

\section{INTRODUÇÃO}

O cenário econômico atual demonstra uma instabilidade de preços ocasionados tanto pela alta taxa de inflação, como pela da taxa básica de juros, e ainda pelos custos elevados de insumos e matérias-primas e de um nível de concorrência crescente. E tal cenário exige das organizações não somente a revisão de seus processos, mas principalmente investimentos em inovação e reinvenção, com o objetivo de obtenção de rentabilidade. Assim, os investimentos realizados pelas empresas podem ser caracterizados pela sua aplicação, podendo estes ser normalmente em caráter de expansão, 
inovação ou substituição. Neste contexto, é relevante frisar que para qualquer tipo de investimento, é necessário avaliar a sua viabilidade econômica e financeira, tendo em vista por um lado, a existência de outras opções no momento da tomada de decisão empresarial, e por outro, a minimização de riscos, bem como a maximização de resultados.

Considerando o exposto, o presente trabalho buscou identificar quais os segmentos econômicos que mais utilizaram as técnicas de análise de investimentos, a saber: Valor Presente Líquido (VPL), Taxa Interna de Retorno (TIR) e Período de Payback, no período 2010-2015 para demonstrar a viabilidade dos projetos que pretendiam implantar, por meio da análise das pesquisadas publicadas no Banco de Teses e Dissertações da Coordenação de Aperfeiçoamento de Pessoal de Nível Superior (Capes). O presente trabalho se justifica por demonstrar a importância da utilização das técnicas de análise de investimentos na minimização dos riscos dos projetos, assim como da potencialização de seus resultados.

\section{METODOLOGIA}

Essa pesquisa, segundo o seu tipo, caracteriza-se como: qualitativa, descritiva e bibliográfica. É qualitativa, pois segundo Gerhardt e Silveira (2009, p. 31) a pesquisa qualitativa não tem preocupação com aspectos numéricos, mas sim com o aprofundamento da compreensão de um grupo social [...] defendendo um único modelo de pesquisa para todas as ciências, uma vez que a ciência social apresenta uma especificidade pressupondo uma metodologia própria. Descritiva porque observa, registra, analisa e interliga fenômenos ou fatos variáveis sem alterá-los, buscando descobrir com nível de precisão elevado, a frequência com que o mesmo ocorre, sua relação e conexão com outros, e suas características (CERVO, BERVIAN, SILVA, 2007, p. 61). Bibliográfica, pois segundo os dizeres de Fonseca (apud GERHARDT; SILVEIRA, 2009, p. 32) realiza um levantamento de referencial teórico já analisado, e divulgado por meios escritos e eletrônicos, como livro, artigos eletrônicos, pagina de websites e outras fontes.

Para a coleta de dados, foi realizada a pesquisa bibliográfica, que segundo Cunha (1985) é um método de pesquisa que permite encontrar uma quantidade restrita de periódicos (portfólio bibliográfico) que se supõe possuir os artigos mais relevantes publicados sobre um tema específico. Deste modo, o estudo bibliográfico visa identificar o que foi produzido pela comunidade científica a respeito de um determinado tempo, e ao mesmo tempo, avaliar as principais tendências sobre o mesmo. Assim, foi realizado inicialmente o levantamento dos artigos científicos que versaram sobre o assunto tratado nesta pesquisa no Banco de Teses e Dissertações da Capes, e após, os artigos selecionados foram analisados.

\section{APRESENTAÇÃO E ANÁLISE DOS RESULTADOS}

A intensa busca por vantagens competitivas que potencialize a lucratividade e a rentabilidade no cenário atual, demanda das organizações de diversos segmentos, constantes investimentos, sejam eles em expansão, inovação ou substituição, para que possam alcançar seus objetivos. Tais investimentos são realizados pelas empresas por meio de projetos, possuindo características específicas, onde segundo os dizeres de Rêgo (2013, p. 17) podem ser de expansão através da aquisição de ativos imobilizados para potencializar a produção, participação no mercado ou área geográfica; de substituição, pelo simples fato de substituir ou renovar ativos obsoletos ou desgastados, incluindo sua reposição; de modernização, através da reconstrução ou adaptação de uma máquina já existente para torná-la mais eficiente; e intangíveis, englobando gastos com propaganda, treinamentos, consultorias, entre outros.

De acordo com Hoji (2003, p. 170) as decisões de investimento para um projeto devem ser cautelosamente analisadas, com base em informações fidedignas pela questão de que comprometem os recursos de uma organização no longo prazo, tornando possível a análise de seus retornos somente no presente momento, gerando algumas incertezas.

Neste contexto, para que seja possível escolher qual o melhor investimento a ser feito, priorizando suas consequências, faz-se necessário analisar a sua viabilidade econômica e financeira, por meio de instrumentos práticos, rápidos e seguros, e que possam efetivamente auxiliar os profissionais no processo de tomada de decisões financeiras (REBELATTO, 2004, p. 140).

\section{TÉCNICAS DE VIABILIDADE ECONÔMICO- FINANCEIRA}

Para melhor entendimento sobre a importância de utilização das técnicas de análise 
de investimentos estudadas pelas empresas pesquisadas, faz-se necessário a apresentação das mesmas a seguir.

\section{Valor Presente Líquido}

Sendo considerado um dos conceitos mais usuais na análise de investimentos, a aplicação do Valor Presente Líquido (VPL), consiste em concentrar na data zero ou comumente denominado ano zero, o valor presente de todos os fluxos de caixa do investimento, sendo estes descontados pela taxa mínima de atratividade, demonstrando o lucro econômico real do projeto (MACEDO ; CORBARI, 2014 , p. 63). Outra definição meritória referente ao método do VPL é mencionada por Samanez (2007), como sendo:

$$
\begin{aligned}
& \text { "O método do valor } \\
& \text { presente líquido (VPL) tem } \\
& \text { por finalidade calcular, em } \\
& \text { termos de valor presente, o } \\
& \text { impacto dos eventos futuros } \\
& \text { associados a uma alternativa } \\
& \text { de investimento, ou seja, ele } \\
& \text { mede o valor presente dos } \\
& \text { fluxos de caixa gerados pelo } \\
& \text { projeto ao longo de sua vida } \\
& \text { útil. Não existindo restrição } \\
& \text { de capital, argumenta-se que } \\
& \text { esse critério leva a escolha } \\
& \text { ótima, pois maximiza o valor } \\
& \text { da empresa". }
\end{aligned}
$$

Hoji (2003, p. 85) contextualiza VPL como sendo a soma das entradas e saídas de um fluxo de caixa em sua data inicial, sendo assim, torna possível a compreensão da sua aplicabilidade, pois ao considerar valor presente do projeto, auxilia o processo decisório demonstrando qual o real valor que o mesmo investimento agrega para a organização, possibilitando decisões mais assertivas.

\section{Taxa Interna de Retorno}

A Taxa Interna de Retorno (TIR) é considerada uma técnica de avaliação de investimentos correspondente à taxa de desconto que iguala o valor presente das entradas de caixa ao investimento inicial, e em relação à análise de projetos, caso o mesmo apresente uma taxa interna de retorno superior à sua taxa mínima de atratividade, é passível de aceitação (MACEDO ; CORBARI, 2014, p.67). Ching, Marques e Prado (2003) ressalta que a TIR não tem como finalidade avaliar a rentabilidade sobre determinado custo do capital (processo de atualização), da mesma forma que o método do valor presente líquido, tendo como foco encontrar uma taxa intrínseca de rendimento, sendo caracterizada como a taxa de retorno do investimento.

A importância desta taxa para uma analise de investimentos é que segundo Cavalcante e Zeppelini (2014) o seu resultado indica se um investimento irá ou não valorizar a organização.

A grande vantagem do método da TIR sobre a metodologia do VPL, é que ela expressa seus resultados através de taxas percentuais, facilitando a interpretação e assimilação do seu resultado, concretizando praticidade e rapidez na análise (MACEDO ; CORBARI, 2014, p.71).

\section{Payback}

O Payback ou comumente denominado tempo de retorno expõe o tempo necessário seja ele em anos, meses ou dias, para recuperação do investimento inicial aplicado no projeto (MEGLIORINI ; VALLIM, 2009).

Ainda conceituando o termo, Camargo (2007) o descreve como o tempo em que o investimento inicial leva para ser recuperado, relatando que o cálculo do mesmo pode ser feito pela análise dos valores de acordo com a sua ocorrência ao longo do tempo ou simplesmente pelos valores descontados. O método do tempo de retorno Payback visa analisar o grau de risco do projeto frente às possibilidades de mudanças no cenário econômico, sendo assim quanto mais o "payback" se aproxima do final do planejamento, maior o risco do projeto (CAMARGO, 2007).

A utilização dessa técnica é subdividida em duas vertentes, o método do Payback simples, e o payback descontado, sendo o primeiro, conceituado como o período em que o investimento inicialmente dispendido leva para ser recuperado, utilizando como base de cálculo os valores originais ao longo do tempo (MACEDO ; CORBARI, 2014, p.72).

Macedo e Corbari (2004, p. 74), ainda relatam que no Payback descontado é demonstrado o período de retorno do valor investido, porém todos os fluxos de análise são descontados à taxa mínima de atratividade escolhida para o projeto, justamente para eliminar o risco do método simples, de não 
considerar o valor do dinheiro no tempo, ou custo de oportunidade do capital.

As organizações podem eleger o método do Payback como um dos critérios de seleção de projetos, com o objetivo de reduzir seus riscos, pois apesar de ser um método simples, é na prática muito utilizado para medir o valor econômico de cada proposta, por apresentar como vantagem a demonstração da liquidez do projeto, e por consequência avaliar o risco da não recuperação do investimento (REBELATTO, 2004, p. 230).

\section{RESULTADOS E DISCUSSÕES}

Para que fosse possível atingir o objetivo principal proposto neste trabalho, foi utilizada como fonte de coleta de dados, a pesquisa bibliométrica, a qual foi baseada na análise das pesquisas publicadas na Capes, tendo como palavras-chave de busca o nome das técnicas de análise de investimentos: Valor Presente Líquido, Taxa Interna de Retorno e Payback.

A consulta resultou em 116 pesquisas, distribuídas entre artigos, teses e dissertações, dos mais variados segmentos e sem determinação de período de tempo, ou seja, a pesquisa resultou em pesquisas consideradas antigas e recentes.

Com o intuito de refinar a análise, as pesquisas foram filtradas para que fosse possível visualizar somente aquelas publicadas entre os anos de 2010 e 2015, o que acabou resultando em 38 pesquisas e na possibilidade de detalhar a aplicabilidade das técnicas de análise de investimentos utilizadas na atualidade, bem como na possibilidade de se encontrar quais as regiões que mais utilizaram estas, e principalmente, qual o segmento de mercado atual que dispõe do uso destas ferramentas como fonte de análise para tomada de decisões.

Por meio da análise, foi constatado que $70 \%$ da concentração de pesquisas foram realizadas nas regiões sul e sudeste do Brasil, sendo que $80 \%$ destas tem relação direta com o setor agropecuário, e o restante, $20 \%$ possuem como temática central a sustentabilidade ambiental por apresentar novas propostas de práticas de produção que possibilitam redução dos impactos ambientais, e ao mesmo tempo a viabilidade econômica, a fim de equilibrar essa equação.

A grande incidência de projetos na área do agronegócio (pecuária e agrícola), provavelmente deve-se a constante necessidade de se analisar os custos de produção e as variações de receita desse setor, o que torna necessário a aplicação de técnicas de análise de investimentos para verificação da viabilidade do negócio.

Além do exposto, foi possível constatar que todas as 38 pesquisas analisadas demonstraram a viabilidade econômica e financeira do projeto proposto, o que reforça a importância da utilização das técnicas de análise de investimento como fonte de informação para readequação de projetos que apresentem inviabilidade antes de sua implantação, minimizando os riscos e potencializando seus resultados através da tomada de decisão mais eficiente.

\section{REFERÊNCIAS}

CAMARGO. C. Análise de investimentos e demonstrativos financeiros. Curitiba: Ibpex, $2007 . \quad$ Disponível em: <unoeste.bv3.digitalpages.com.br/users/publicati ons/9788587053817/pages/5> Acesso em: 30 mai 2016.

CAVALCANTE, F. ; ZEPPELINI, P. D. Taxa interna de retorno (TIR): perguntas mais frequentes. São Paulo: Cavalcante e Associados, 2014. Disponível em:

$<$ www.cavalcanteeassociados.com.br/utd/UpToD ate145.pdf>. Acesso em: 07 mai 2016.

CERVO, A. L. ; BERVIAN, P. A. ; SILVA, R. Metodologia científica. 6. ed. São Paulo: Pearson, 2007. Disponível em: < http://unoeste.bv3.digitalpages.com.br/users/pu blications/9788576050476/pages/_3>. Acesso em: 01 Jun 2016.

CHING, H. Y. ; MARQUES, F. ; PRADO, L. Contabilidade e finanças para não especialistas. São Paulo: Pearson Prentice Hall, 2003. Disponivel em: <unoeste.bv3.digitalpages.com.br/users/publicati ons/9788587918611/pages/_3>. Acesso em 31 de mai 2016.

CUNHA, M. V. Os periódicos em Ciência da Informação: uma análise bibliométrica. Ciência e Informação, Brasília, v. 14, n. 1, 1985. Disponível em:

$<$ http://www.revista.ibict.br/ciinf/article/view/22 5>. Acesso em: 01 set 2016.

GERHARDT, T. E.; SILVEIRA, D. T. Métodos de pesquisa. Rio Grande do Sul: UFRGS, 2009. Disponível em: <http://www.ufrgs.br/cursopgdr/downloadsSerie /derad005.pdf >. Acesso em: 29 mai 2016. 
MACEDO, J. J. ; CORBARI, E. C. Análise de projeto e orçamento empresarial. Curitiba: Intersaberes, 2014.

MEGLIORINI, E. ; VALLIM, M. A. Administração financeira: uma abordagem brasileira. São Paulo: Pearson Prentice Hall, 2009. Disponível em <unoeste.bv3.digitalpages.com.br/users/publicati ons/9788576052067/pages/_7> Acesso em: 02 jun 2016.

REBELATTO, D. Projeto de investimento. Barueri : Manole, 2004.

RÊGO, R. B. et al. Viabilidade econômicofinanceira de projetos. 4. ed. Rio de Janeiro: FGV, 2013.

SAMANEZ, C. P. Gestão de investimentos e geração de valor. São Paulo. Pearson Prentice Hall, 2007.

Recebido para publicação em 26/08/2016

Revisado em 02/09/2016

Aceito em 06/09/2016 